\title{
Evaluating the Metrics of Research Performance in $H$-Index and Scientific Quality Index among Indian Dental Researchers
}

\author{
Prashanthy.M.R ${ }^{1}$, Rajmohan.M ${ }^{2}$, Bharathwaj.V.V ${ }^{3}$, Sindhu.R ${ }^{3}$, \\ Dinesh Dhamodhar ${ }^{2}$, Shreelakshmi.S ${ }^{3}$, Prabu.D ${ }^{4}$, Suganya.P ${ }^{1}$ \\ ${ }^{1}$ Postgraduate Student, ${ }^{2}$ Reader, ${ }^{3}$ Senior Lecturer, ${ }^{4}$ Head and Professor of the Department, \\ Department of Public Health Dentistry, SRM Dental College and Hospital, Ramapuram
}

Corresponding Author: Prabu.D

\begin{abstract}
Aim: This study aimed to calculate the scientific output of researchers in selected branches of dentistry using h-index and scientific quality index.

Methodology: Data were retrieved from the google scholar (2013-2018) in the eight departments of dentistry. The professors from the faculty of dentistry were randomly selected and among the scientific data were collected by the tool together with year of publication, number of citations, number of published papers, number of papers cited more than 10 times. It was analyzed by the H-index and newly proposed scientific quality index (SQI).

Results: The SQI expresses mainly the qualitative features of scientific output, whereas the $\mathrm{H}$-index is more influenced by its quantitative measures.

Conclusion: The SQI might be considered as a novel marker of scientific yield quality, though the h-index is more grounded controlled by quantitative measures.
\end{abstract}

Keywords: Citation, $\mathrm{H}$-index, individual output, scientific quality index, Dentist

\section{INTRODUCTION}

Research is a growing field for so many decades and has been still a thirst of so many research scholars to place in a good and highest impact factor journal. Various methods to evaluate scientific papers of discrete researchers. Researchers can be figured out the number of citations, number of papers in which a given author is either the first or senior author and citation index. The purpose of assessing both the quantity and quality of research-based activity was advanced by Hirsch ${ }^{1}$. The h-index is a number described to constitute both the yield and the impact of certain researchers, or a category of researchers or scholars.

Hirsch suggested an indigenous, simple indicator categorize the progressive collision of the scientific work of independent researchers- $\mathrm{N}$ papers have maximum citations each and the other papers have no more than h citations. Over the last decade, most widely used index was Hirsch $^{2}$. The SQI formula clearly indicates SQI to be strongly influenced by highly cited papers, so it is expected that SQI, in comparison to the h-index, should be more related to science quality but less dependent on the overall quantity of publications ${ }^{3}$. Assessing the scientific outcomes of scientist by the scientometrics experts and it always $\mathrm{H}$-index has been reviewed ${ }^{4}$.

Bibliometrics enables researchers to explore the impact of a specific field. In a certain sense, it is a citation index that is now widely accepted as a measurement of recognition, although it is not a measurement of quality or importance ${ }^{5}$. Introduced many applied sciences have extraordinary prospective for the undeviating and less costly spreading of scientific outputs ${ }^{6}$. 
Prashanthy.M.R et.al. Evaluating the metrics of research performance in h-index and scientific quality index among Indian dental researchers

\section{METHODOLOGY}

Data were retrieved from the google scholar (2013-2018) in the category of Public Health Dentistry, Oral Maxillofacial Surgery, Orthodontics, Pedodontics, Prosthodontics, Conservative Dentistry and Endodontics, Oral Medicine and Radiology, Oral Pathology and Microbiology. The professors from the faculty of dentistry were randomly selected and among the scientific data were collected by the tool together with year of publication, number of citations, number of published papers, number of papers cited more than 10 times. It was analyzed by the H-index and newly proposed scientific quality index (SQI).To know which article has more number of citation and first entered all the cited articles in excel sheet and from that we tabulated the results based on highest citation.

\section{Inclusion Criteria}

Each scientific field was represented by minimum authors of each department in dentistry with the number of cited papers, and considering the $\mathrm{H}$-index of each author, recorded during 5year

\section{Exclusion Criteria}

The exclusion of self citations and same articles cited more times, same author name in different faculty is included in that google scholar were excluded, the percent of cited papers below 10 times, including with no citation. Other than English languages articles were excluded.

\section{Scientific Quality Index}

Using the Bibliometrics Parameters and data were derived from the google scholar, new index SQI was calculated for each of the analysed scientists, according to the to the following formula

Parameter No.1 added up with Parameter No.2, where

Parameter No.1: The percent of papers cited $\geq 10$ times equal to the number of papers cited $\geq 10$ times divided by the number of all the published paper multiply with 100percentage.

Parameter No.2: The mean number of citations per paper equal to the total number of citations divided by the number of all published papers.

\section{RESULTS}

\begin{tabular}{|c|c|c|c|c|}
\hline Author And Faculty & Total Citation & Number Of Articles & $\begin{array}{l}\text { Number Articles Cited } \\
\text { More Than } 10 \text { Times }\end{array}$ & H' Index \\
\hline \multicolumn{5}{|l|}{ Oral Maxilofacial Surgery } \\
\hline Dr S.M. Balaji & 756 & 151 & 5 & 13 \\
\hline \multicolumn{5}{|l|}{ Pedodontics } \\
\hline Dr Ms Muthu & 1154 & 85 & 3 & 21 \\
\hline Dr Vineet Dhar & 1125 & 58 & 8 & 13 \\
\hline \multicolumn{5}{|l|}{ Orthodontics } \\
\hline Dr Sridhar Premkumar & 187 & 25 & 1 & 8 \\
\hline \multicolumn{5}{|l|}{ Public Health Dentistry } \\
\hline Dr Prabu D & 1567 & 116 & 10 & 20 \\
\hline Dr Shashidhar Acharya & 1591 & 129 & 17 & 21 \\
\hline Dr Chandrashekhar Janakiraman & 270 & 49 & 3 & 8 \\
\hline \multicolumn{5}{|l|}{ Prosthodontics } \\
\hline Dr Deepak Nallaswamy & 149 & 12 & 1 & 5 \\
\hline Dr Gopi Chander & 116 & 50 & 1 & 6 \\
\hline Kamalakanth Shenoy & 338 & 72 & 3 & 11 \\
\hline \multicolumn{5}{|l|}{ Oral Pathology And Microbiology } \\
\hline Dr Renganathan K & 3296 & 179 & 10 & 29 \\
\hline Dr Vijay Wadhwan & 366 & 74 & 5 & 12 \\
\hline \multicolumn{5}{|c|}{ Conservativedentistryandendodontics } \\
\hline Dr Nisha Garg & 233 & 41 & 22 & 40 \\
\hline Dr Sangeetha Talwar & 830 & 82 & 13 & 15 \\
\hline \multicolumn{5}{|l|}{ Oral Medicine And Radiology } \\
\hline Dr Keerthilatha M Pai & 2383 & 198 & 3 & 24 \\
\hline \multicolumn{5}{|l|}{ Periodontics } \\
\hline Dr Ajay Mahajan & 308 & 47 & 1 & 8 \\
\hline Dr Raghavendra Reddy Nagate & 233 & 45 & 1 & 9 \\
\hline Dr Haritha Avula & 218 & 25 & 3 & 10 \\
\hline
\end{tabular}


Prashanthy.M.R et.al. Evaluating the metrics of research performance in h-index and scientific quality index among Indian dental researchers

The table 1 represented that selected authors in all the departments must have higher citations, number of published papers, number of citation more than 10times.

The mean values of the basic bibliometric parameters, describing the individual scientific outputs of selected scientists. When the evaluated investigators were ranked by decreasing SQI values, only two authors maintained their baseline positions by decreasing $\mathrm{H}$-index.

Table 2: Scientific Quality Index and H-Index Values for dental researcher

\begin{tabular}{|l|l|c|c|}
\hline \multicolumn{1}{|c|}{ Author Name } & \multicolumn{1}{|c|}{ Dental Stream } & Scientific Quality Index(Sqi) & H Index \\
\hline Sm Balaji & Oral Maxillofacial Surgery & 8.32 & 13 \\
\hline Dr Ms Muthu & Pedodontics & 17.11 & 21 \\
\hline Dr Vineet Dhar & Pedodontics & 33.19 & 13 \\
\hline Dr Sridhar Premkumar & Orthodontics & 11.48 & 8 \\
\hline Dr Prabu D & Public Health Dentistry & 22.13 & 20 \\
\hline Dr Shashidhar Acharya & Public Health Dentistry & 25.51 & 21 \\
\hline Dr Chandrasekhar Janakiraman & Public Health Dentistry & 11.63 & 8 \\
\hline Dr Deepak Nallaswamy & Prosthodontics & 20.75 & 5 \\
\hline Dr Gopichandar & Prosthodontics & 4.32 & 6 \\
\hline Dr Kamalkanth Shenoy & Prosthodontics & 8.86 & 11 \\
\hline Dr Renganathan K & Oral Pathology And Microbiology & 24.00 & 29 \\
\hline Dr Vijay Wadhwan & Oral Pathology And Microbiology & 11.70 & 12 \\
\hline Dr Nisha Garg & Conservative Dentistry And Endodontics & 59.34 & 40 \\
\hline Dr Sangeetha Talwar & Conservative Dentistry And Endodontics & 25.98 & 15 \\
\hline Dr Keerthilatha M Pai & Oral Medicine And Radiology & 13.55 & 24 \\
\hline Dr Ajay Mahajan & Periodontology & 8.68 & 9 \\
\hline Dr Raghavendra Reddy Nagate & Periodontology & 20.72 & 10 \\
\hline Dr Haritha Avula & Periodontology & & \\
\hline
\end{tabular}

The table 2 represented individual SQI and $\mathrm{H}$-index values for researchers, including oral maxillofacial surgeon, three periodontist, one oral medicine and radiology, two pedodontists, one orthodontist, three prosthodontist, two oral pathologist, three public health dentist. The highest value was achieved by Dr. Renganathan, an oral pathologist. The highest SQI value was achieved by $\mathrm{Dr}$ Nisha Garg, conservative dentistry and endodontist.

Table3: Correlation for the H-Index and SQI Scores

\begin{tabular}{|l|c|c|}
\hline & H- INDEX & SQI \\
\hline Number of publications & $0.721(\mathrm{P}<0.001)$ & $0.166(\mathrm{p}-0.497)$ \\
\hline Number of citations & $0.813(\mathrm{P}<0.001)$ & $0.448(\mathrm{p}-0.054)$ \\
\hline Number of papers cited $\geq 10$ times & $0.826(\mathrm{P}<0.001)$ & $0.754(\mathrm{p}<0.001)$ \\
\hline Percent of papers cited $\geq 10$ times (SQI first parameter) & $0.292(\mathrm{P}-0.225)$ & $0.835(\mathrm{p}<0.001)$ \\
\hline Mean citations per paper (SQI second parameter) & $0.463(\mathrm{P}-0.046)$ & $0.726(\mathrm{p}<0.001)$ \\
\hline
\end{tabular}

The results of a correlation analysis between H-index and SQI scores and the selected basic Bibliometrics parameters. All the presented correlation coefficient values demonstrate significant differences between SQI and h-index scores.

\section{DISCUSSION}

The current study aimed to carry out a pre-defined and structured appraisal of scientific outputs in a group of researchers, representing dental areas, identified by selected authors. The initial evaluating of the study attentive to the various situation of the analyzed researchers, obtained by the h-index or by the SQI. A Paired positions of selected researcher and the grouping with dental fields conveys the differences. MS Muthu Pedodontist author published 85 papers but all of them were cited less than 10 times. Such a large discrepancy between these two, so distinct results obviously indicate that the quantitative and qualitative tables representing an individual investigators science performance may be completely unrelated.

SM. Balaji an oral surgeon has published nearly 155 papers, out of which, 60 were cited many times. Dr Keerthilatha 
M pai, an oral medicine researcher has 198 published papers. Dr Prabu D-public health dentist has 116 published papers, out of which 50 were cited many times. Dr Kamalakanth Shenoy, a prosthodontist has 78 published papers. It is a good example of an impressive output in terms of its quantity, however, most of the published papers either found no citations or were cited less than 10 times and the average number of citations per paper was only 7.5. Such an individual may then be portrayed as somebody with an extremely high production. Simply quantitative Bibliometrics markers place the creator extremely high in positioning, while the SQI uncovers the somewhat normal nature of logical work. That is the reason we consider SQI as the subjective parameter chiefly.

The impact of various elements, applied on both files and distinguished in the investigation of relationship, appears to have been in charge of the watched contrasts between h-index and SQI. The SQI, substantially more than the h-index, focuses on subjective highlights in the logical yield of an individual examiner. The significance of quantitative factors, such as the number of publications, the number of citations, the number of cited papers and the number of papers cited $\geq 10$ times, is by all accounts considerably less significant in the SQI approach than it is in the h-index evaluation. Unexpectedly, the variables more identified with logical quality than amount. This investigation evaluated among the reference is higher and more Bibliometrics examination in reference dental scientists.

Strangely enough, the coefficient of relationship, determined between the h-list and SQI as $(0.75) \quad(\mathrm{p}<0.001)$. This perception may bolster the proposition of a redundant connection between the more subjective SQI values and the more quantitative h-index figures in various examination gatherings. Then again, it doesn't imply that the estimation of one record might be effectively 'anticipated' from the estimation of the subsequent list. It could be conceivable when the relationship coefficient was $>0.01$ yet when it is around 0.75 , we may at present expect an expansive scope of components that impact h-index and SQI brings about various ways.

Most recent research by Glanville and associates saw on yields from dental research in the UK, USA, CANADA, AUSTRALIA, and GERMANY and THE NETHERLANDS. The normal h-index for scientists from UK was 13 , to some degree lower than worth. The distinction may have emerged as an outcome of our utilization of google researcher which will in general record more prominent number of publications ${ }^{7}$.

Besides, thinks about has been depicted that h-index scores can diminish, yet in addition SQI-qualities may not just expands dissimilar to diminish if the nature of an individual logical yield gets any lesser qualities and it indicated by the percent of papers, referred to in any event 10times and the mean citation per paper. SQI has one of a kind elements for both the factors are make it discrete from other Bibliometrics parameters with only single direction, upward changes their scores. This element of SQI ought to be considered as most significant for longitudinal evaluation of the nature of research of an individual specialist.

The current hypothesis of SQI and our present study talks about some restraint though. Budding authors with a less output cannot be adequately assessed by this method. SQI is based on the mean citation scores, whereas in case of some authors, their individual median of citation per paper could much better reflect their actual contribution. In the future, it would be interesting to develop an algorithm for normalization of SQI scores among different science disciplines, to compensate for unequal chances to achieve high index values in some research areas.

In the present investigation, the SQI esteems were contrasted just and the h- 
record while extra examinations with different pointers are to be considered, for example with the mean normalized citation score (MNCS) or the mean citation score. We chose to contrast the introduced SQI and the maybe most broadly utilized Bibliometrics marker h-index to make the introduction as clear as could be expected under the circumstances. The underlying choice of the creators in each logical region depended on the quantity of every one of their productions. In the ensuing advance, the situation for each creator was built up by the h-index without auto-citation and citation of all co-creators. It implies that a few creators, not positioned inside the underlying rundown of toppers, had a higher h-index scores than the last subject in the top rundown however they couldn't be considered. The essential objective of the present examination was to feature the distinctions in the evaluation of an individual creator's logical yield between h-index and SQI scoring modalities and not give the customized records.

\section{Limitations}

Since, too many top researchers are not yet updated in google scholar. It was unable to get h-index from top researchers. Name of the dental researchers have similar names in other faculty researchers are additionally included google scholar and it was a fundamental drawback of it. Some dental researchers have high h-index but published papers are to less because self-citations are more in h-index.

\section{CONCLUSION}

An appraisal of the individual logical yield of creators from 8 research areas was acquired in the present investigation, demonstrating contrasts in places of the creators between the h-index and the SQI estimates. Albeit emphatically associated, the h-index and SQI figures compare to some degree various parts of individual research yield. The SQI might be considered as a novel marker of scientific yield quality, though the h-index is more grounded controlled by quantitative measures.

\section{Acknowledgement: None}

Conflict of Interest: None

\section{Source of Funding: None}

\section{REFERENCES}

1. Hirsch JE. An index to quantify an individual's scientific research output. Proceedings of the National academy of Sciences. 2005 Nov 15; 102(46):16569-72.

2. Pluskiewicz W, Drozdzowska B, Adamczyk P, Noga K. Scientific output quality of 40 globally top-ranked medical researchers in the field of osteoporosis. Archives of osteoporosis. 2018 Dec 1;13(1):35.

3. Pluskiewicz W, Drozdzowska B. A novel indictor of the scientific quality in academic medical researchers.

4. Ahangar HG, Siamian H, Yaminfirooz M. Evaluation of the scientific outputs of researchers with similar $\mathrm{h}$ index: a critical approach. Acta Informatica Medica. 2014 Aug;22(4):255.

5. Bornmann L, Daniel HD. What do we know about the $\mathrm{h}$ index?. Journal of the American Society for Information Science and technology. 2007 Jul;58(9):1381-5.

6. Steele C, Butler L, Kingsley D. The publishing imperative: the pervasive influence of publication metrics. Learned Publishing. 2006 Oct;19(4):277-90.

7. Birks Y, Fairhurst C, Bloor K, Campbell M, Baird W, Torgerson D. Use of the h-index to measure the quality of the output of health services researchers. Journal of health services research \& policy. 2014 Apr;19 (2):102-9.

8. Abramo G, D'Angelo CA. A farewell to the MNCS and like size-independent indicators. Journal of Informetrics. 2016 May 1;10(2):646-51.

9. Nieminen $P$, Carpenter J, Rucker G, Schumacher M. The relationship between quality of research and citation frequency. BMC Medical Research Methodology. 2006 Dec;6(1):42.

10. Thelwall M, Sud P. National, disciplinary and temporal variations in the extent to which articles with more authors have more impact: Evidence from a geometric field 
Prashanthy.M.R et.al. Evaluating the metrics of research performance in h-index and scientific quality index among Indian dental researchers

normalised citation indicator. Journal of Informetrics. 2016 Feb 1;10(1):48-61.

11. Xu T, Khalili S, Deng C. A study on factors related to readership of scientific articles. STEM Fellowship Journal. 2017 Dec 22;3(2):1-5.

12. Filion KB, Pless IB. Factors related to the frequency of citation of epidemiologic publications. Epidemiologic Perspectives \& Innovations. 2008 Dec;5(1):3.
How to cite this article: Prashanthy.M.R, Rajmohan.M, Bharathwaj.V.V et.al. Evaluating the metrics of research performance in h-index and scientific quality index among Indian dental researchers. International Journal of Research and Review. 2021; 8(11): 117-122. DOI: https://doi.org/10.52403/ijrr.20211116 